\title{
Burden of Primary Dysmenorrhea -Way Forward
}

\author{
Chhabra $S^{*}$, Yadav S and Gokhale S \\ Department of Obstetrics Gynaecology, Mahatma Gandhi Institute of Medical Sciences, India
}

Submission: February 15, 2018; Published: March 15, 2018

"Corresponding author: Chhabra S, Department of Obstetrics Gynaecology, Mahatma Gandhi Institute Of Medical Sciences, Sevagram, Wardha 4420102, Maharashtra, India, Email: schhabra@mgims.ac.in

Abstract

Background: Though accurate burden of dysmenorrhea is not very well known, it is probably the most common menstrual disorder, may be most common gynecological disorder too. Reported occurrence is as high as 90 percent in women of reproductive age.

Objective: Present prospective study was carried out with the aim of knowing occurrence of dysmenorrhea, relation to Tanner's stage, school absentism.

Material Methods: Postmenarcheal adolescents, 282 school girls were interviewed in their schools. In addition 100 first year medical / nursing students who lived/worked in the same campus, mostly in the same building, willing to be part of the study, were also interviewed. Girls were from rural as well as urban settings, divided according to reporting of presence or absence of dysmennorhoea.

Results: Mean age of menarche in school girls was 13.4 years, in medical and nursing students also it was 13.1 years. In most school girls (53.32\%), pain started in second year after menarche. More of older medical, nursing students reported dysmenorrhoea $(21.6 \%<18$ years old and $81.8 \%$ in $>18$ years old). Tanner staging influenced occurrence of dysmenorrhoea more at a given age than age alone. Many girls remained absent from their schools or work regularly because of dysmenorrhoea. Eighty nine per cent school girls regarded menstruation as physiological event but $11 \%$ thought it was a curse.

Conclusion: Over all dysmenorrhoea was very common. This physiological event needs to be given more attention to decrease absentism from school, work, also help girls to cope better with dysmenorrhea till there is more information about prevention.

\section{Background}

Though an accurate burden of dysmenorrhea is not very well known, it is probably the most common menstrual disorder, may be the most common gynecological disorder too. Probably every woman experiences some pain during menstruation at some or the other time in her life. Also primary dysmenorrhea, menstrual pain in the absence of any identifiable pelvic pathology, is by far the most common gynecological disorder which women fail to report even when asked. It has been reported that as high as 90 percent of girls /women of reproductive age get dysmenorrhea. Schroeder [1] has reported the incidence among adolescents around 92\%. A prospective study based on diaries kept for one year by college students, revealed that 72 percent of monitored periods were painful and Andrew [2] reported that sixty percent of the women studied reported at least one episode of severe pain. Johnson [3] in his study reported $72.7 \%$ incidence. It is the leading cause of periodic short term morbidity in adolescents, which can become a distressing symptom curbing daily activities and causing social withdrawal. It continues to be an important medical problem with financial and social burden to the individual, and society as a whole and hence research needs to continue. Polat et al. [4] in their study found mean age of menarche $13.3 \pm 1.4$ years and $45 \%$ were found to suffer pain in each menstruation and concluded prevalence of primary dysmenorrhea higher than that cited in the literature. George et al. [5] studied the prevalence of dysmenorrhoea among adolescent girls and reported the range from 60 to 83 percent and many adolescents reported limitation on daily activities. A significant association was found between severe dysmenorrhea, absenteism from school/work, and basic level of education. Pain associated with dysmenorrhea is believed to be caused by hypersecretion of prostaglandins and an increased uterine contractility. Unfortunately clinicians have unjustifiably tended to adopt a nihilistic approach dismissing the disorder as a normal physiological event. Sometimes the sufferer is labeled neurotic. At individual level it may generate sufficient fear in anticipation of the next menstruation, so much that mental health of the girl during the intermenstrual phase may be severely compromised. Although it is only temporarily disabling, it`s frequency, regularity and the numbers of sufferers make it worthy of renewed appraisal. 


\section{Objective}

Present prospective study was carried out with the aim of knowing the occurrence of dysmenorrhea, relation to Tanner' stage and school absentism.

\section{Material Methods}

Postmenarcheal 282 adolescent school girls, were interviewed. They were from four schools around the medical institution, where study has been done, selected randomly, depending upon the accessibility from the medical institute, girls' head masters', and parents' permission and willingness to be part of the study. In addition 100 first year medical and nursing students who lived in the same campus, most of the time in the same building, willing to be part of the study, were also interviewed. The study subjects were rural as well as urban. After obtaining necessary consent, they were interviewed with the help of a predesigned questionnaire, developed according to the objectives. Information regarding occurrence of dysmenorrhea and the details as per objectives were collected and analysed. Analysis was done according to the reporting of dysmennorhoea, yes or no.

\section{Results}

Mean age of menarche in school girls was 13.4 years and in medical and nursing students also it was 13.1 years, $60.70 \%$ school girls from upper economic class [6] had menarche between 10-11 years compared to $19.6 \%$ girls from lower middle and middle EC ( $\mathrm{P}=0.0359$, significant difference), $80 \%$ and $83.33 \%$ of upper EC medical/nursing students also had an earlier menarche compared to $28.57 \%$ of lower EC ( $\mathrm{P}=0.005$ highly significant). Overall of 73 urban medical / nursing students, $65.75 \%$ said they suffered dysmenorrhoea and of 27 rural, $51.85 \%$ reported dysmenorrhoea $(\mathrm{P}=0.20$ insignificant difference).Out of 282 school girls, 197(69.85\%) reported dysmenorrhea and 85(30.14\%) school girls said they did not have dysmenorrhea (Table 1). Over all more urban school girls reported dysmenorrhoea than rural, $74.59 \%$ and $60.82 \%$ respectively $((\mathrm{P}<0.016$ significant difference).In most school girls (53.32\%), pain started in second year after menarche. More of older medical and nursing students reported dysmenorrhoea ( $21.6 \%<18$ years old and $81.8 \%$ in $>18$ years old). Dysmenorrhoea increased with chronological age from $56.61 \%$ in girls of $12-13$ years old to $90.90 \%$ in $18-19$ years old school girls $((\mathrm{P}=0.033$ significant difference) (Table 2). Of 153 school girls with gynaecological age (interval from menarche) of one year, 93 $(60.78 \%)$ reported dysmenorrhoea. Of 99 school girls with gyn age of 2-3 years $77(77.70 \%)$ reported dysmenorrhea. Of 30 girls with gyn age 4-7 years, 28 (93.33\%) reported dysmenorrhea. Of 3 Nursing/Medical students with gynae age of 1-3 years, no one had dysmenorrhea, of 50 with gyn age 4-7 years, 25(50\%), of 38 with gyn age of 8-11 years, $30(78.94 \%)$ had dysmenorrhoea and all 9 Nursing/Medical students with gyn age of 12-15 years, had dysmenorrhea. However in the beginning during interviews the reporting of dysmenorrhoea deferred at the same age $<18$ 18 amongst school girls (69\%) and nursing \& medical students (26.66\%) (Table 3). Actually during analysis there was gross difference between medical/nursing students and school girls. Interviews had taken place in the months of July / August, when students had joined the medical / nursing schools. On an informal basis when asked the medical / nursing girls admitted that in the beginning they were shy about revealing their problems and were not sure whether they would be made to seek treatment from senior consultants. So many had said they were not having dysmenorrhoea. Dysmenorrhoea was actually in $73.3 \%$. Over all of 197 girls of 14-15 years, 109 had (55.32\%) dysmenorrhoea. The pain started one year after menarche. Of 9 girls in upper-middle class, $5(55.55 \%)$ had dysmenorrhoea. Of 38 girls of lower class, 29(78\%) had dysmenorrhoea in second year after menarche. Out of 49 girls from upper-middle and middle class, $31(63.26 \%)$ started getting dysmenorrhoea 2 years after menarche. Overall 61 out of 282 girls (21.6\%) missed school, because of dysmenorrhoea, 38 of 185 urban (20.54\%) and 23 out of 97 rural (23.71\%). Of 38 urban, 11 (28.94\%) always missed school, 17 (44.73\%) frequently, 10 (26.31\%) occasionally. Of 23 rural girls 4 (17.39\%) always missed school, $20(32.78 \%)$ for 3 or more days, $10(16.12 \%)$ for 2 days and 30 (49.18\%) for one day,39 girls out of 177 (22.03\%) of lower middle and lower economic class missed school and 21 of 102 (20.58\%) upper middle and middle class missed school (Table 4). Over all 42 of 100 nursing/medical students also said they missed school, 7 of 27 (25.92\%) rural and 35 of 73 (47.94\%) urban $(\mathrm{P}=0.0476$ significant difference). Of 35 urban girls, 11 (31.43\%) always missed school, 13 (37.14\%) frequently and 11 (31.43\%) occasionally. Of 7 rural girls, $2(28.57 \%)$ missed school frequently, one $(14.28 \%)$ always and $4(57.14 \%)$ occasionally. Of 42 girls with school absentism,10(23.80\%) missed school for 3 or more days, $13(30.95 \%)$ for 2 days and 19 (45.23\%) for one day (Table 5). Of 29 school girls of 12-13 years with dysmennorhoea, $21(72.41 \%)$ had described moderate pain, of whom $3(14.85 \%)$ missed school and one with severe pain, always missed school. of 40 girls of $16-17$ years, $29(72.5 \%)$ described pain as moderate, $9(31.03 \%)$ of them missed school and all 8 girls with severe pain, missed school. Of 20 girls between $19-20$ years, $6(30 \%)$ described pain as mild and one (16.66\%) of them missed school and $8(40 \%)$ with severe, pain always missed school. Of 29 girls between $21-22$ yrs, 8 (27.5\%) described pain as mild of whom one $(12.55 \%)$ missed school and $15(51.24 \%)$ described pain as severe $(86.6 \%)$ of them missed school (Table 4 \& Table 5). Thirty nine girls of 177 middle-lower and lower class missed school and 21 out of 102 (20.58\%) and girls from upper middle and middle class missed school. Forty two of 100 medical / nursing girls missed school, 7 of 27 (25.92\%) rural and 35 of 73 (47.94\%) urban. Of 35 urban girls, 11 (31.43\%) always missed school, 13 (37.14\%) frequently and 11 (31.43\%) occasionally. Of 7 rural, $2(28.57 \%)$ always missed school, one (14.28\%) sometimes and $4(57.14 \%)$ occasionally. Of 42 girls who missed school, 10 $(23.80 \%)$ missed school for more days, 13 (30.95\%) for 2 days 
and 19 (45.23\%) for one day. Dysmenorrhoea also increased with sexual maturity from $38 \%$ at age 10 years with Tanner stage 3 to $66 \%$ at age 10 years with Tanner stage 5 and from $31 \%$ one year post menarche to $78 \%$ five years post menarche. In girls between 14-15 yrs. 64\% had dysmenorrhoea and it increased to $83.33 \%$ in $16-17$ yrs old. However in $14-15$ yrs old, $50 \%$ of girls in Tanner stage III had dysmenorrhoea and $90.12 \%$ of girls in Tanner stage IV had dysmenorrhoea. Similarly, $41.6 \%$ of girls between 16-17 yrs. at Tanner stage III had dysmenorrhoea compared to $96.55 \%$ at Tanner stage IV. Thus, Tanner staging influenced prevalence of dysmenorrhoea, more at a given age than when age was considered alone. In upper and uppermiddle class girls of $14-15$ yrs. $62.5 \%$ girls had dysmenorrhoea with Tanner stage III and 93\% had dysmenorrhoea at Tanner stage IV and in middle-lower and lower class girls, $45.45 \%$ had dysmenorrhoea at Tanner stage III and $88.23 \%$ at Tanner stage IV. Though dysmenorrhoea was slightly less often in the middle- lower and lower class compared to upper and upper-middle class $(65.4 \%$ as against $76.2 \%$ respectively) dysmenorrhoea frequency increased from Tanner III to Tanner IV in both groups of same age girls from different socio-economic strata. Frequency of dysmenorrhoea increased from $49.6 \%$ at Tanner stage III to $90.83 \%$ at Tanner stage IV ( $\mathrm{P}=0.0001$, significant) and though there were 17 girls of Tanner stage $\mathrm{V}$ in the school survey, all of them had dysmenorrhoea putting the frequency at $100 \%$ in the present analysis. Of 42 girls with severe pain, 10 (23.80\%) belonged to Tanner stage $\mathrm{V}$ and of 35 girls with mild pain only 1 (2.8\%) belonged to Tanner stage V. Of the 119 girls with Tanner stage IV, $72(60.5 \%)$ described the pain as moderate and 30 $(25.2 \%)$ described the pain as severe. Of 17 girls in Tanner stage V, 10 girls (58.82\%) described the pain as severe. Eighty nine per cent school girls regarded menstruation as physiological event but $11 \%$ thought it was a curse.

Table 1: Age, Residence \& Presence or Absence of dysmenorrhoea Among School Girls and Medical and Nursing Students.

\begin{tabular}{|c|c|c|c|c|c|}
\hline \multirow{3}{*}{ Age (Yrs) } & Rural & & Urban & & \multirow{3}{*}{ Total } \\
\hline & Schol Girls & & School Girls & & \\
\hline & DP* & DA* & DP & DA & \\
\hline $10-\mathrm{Nov}$ & 0 & 1 & 0 & 0 & 1 \\
\hline Dec-13 & 3 & 9 & 26 & 13 & 51 \\
\hline $14-15$ & 38 & 23 & 80 & 30 & 171 \\
\hline $16-17$ & 18 & 5 & 22 & 3 & 48 \\
\hline $18-19$ & - & - & 10 & 1 & 11 \\
\hline \multirow[t]{2}{*}{ TOTAL } & 59 & 38 & 138 & 47 & 282 \\
\hline & \multicolumn{2}{|c|}{ Medical Nursing Students } & \multicolumn{2}{|c|}{ Medical Nursing Students } & \\
\hline$<18-18$ & 0 & 3 & 4 & 8 & 15 \\
\hline $19-20$ & 7 & 6 & 13 & 13 & 39 \\
\hline $21-22$ & 5 & 4 & 24 & 2 & 35 \\
\hline $23-24$ & 2 & 0 & 7 & 2 & 11 \\
\hline Total & 14 & 13 & 48 & 25 & 100 \\
\hline
\end{tabular}

${ }^{*} \mathrm{DP}=$ Dysmenorrhoea Present

${ }^{*} \mathrm{DA}=$ Dysmenorrhoea Absent

Table 2: *Age, Gynaecological Age and Presence or Absence of Dysmenorrhoea among School Girls.

\begin{tabular}{|c|c|c|c|c|c|c|c|c|c|}
\hline \multirow{3}{*}{$\begin{array}{l}\text { Ager } \\
\text { (Yrs) }\end{array}$} & \multicolumn{8}{|c|}{ Gynecological Age } & \multirow{3}{*}{ Tota } \\
\hline & \multicolumn{2}{|c|}{$0-1$} & \multicolumn{2}{|c|}{ 02-Mar } & \multicolumn{2}{|c|}{ 04-May } & \multicolumn{2}{|c|}{ 06-Jul } & \\
\hline & DP* & $\mathbf{D A}^{*}$ & DP & DA & DP & DA & DP & DA & \\
\hline \multirow[t]{8}{*}{ Dec-13 } & 0 & 0 & 0 & 0 & 0 & 0 & 0 & 0 & 0 \\
\hline & 0 & 1 & 0 & 0 & 0 & 0 & 0 & 0 & 1 \\
\hline & 9 & 4 & 0 & 0 & 0 & 0 & 0 & 0 & 13 \\
\hline & 16 & 9 & 0 & 0 & 0 & 0 & 0 & 0 & 25 \\
\hline & 1 & 4 & 0 & 0 & 0 & 0 & 0 & 0 & 5 \\
\hline & 3 & 1 & 1 & 0 & 0 & 0 & 0 & 0 & 5 \\
\hline & 0 & 2 & 0 & 0 & 0 & 0 & 0 & 0 & 2 \\
\hline & 0 & 0 & 0 & 0 & 0 & 0 & 0 & 0 & 0 \\
\hline
\end{tabular}




\begin{tabular}{|c|c|c|c|c|c|c|c|c|c|}
\hline \multirow[t]{8}{*}{$14-15$} & 1 & 0 & 0 & 0 & 0 & 0 & 0 & 0 & 1 \\
\hline & 1 & 1 & 1 & 1 & 0 & 0 & 0 & 0 & 4 \\
\hline & 20 & 5 & 12 & 1 & 0 & 0 & 0 & 0 & 38 \\
\hline & 27 & 19 & 17 & 8 & 1 & 0 & 0 & 0 & 72 \\
\hline & 8 & 5 & 17 & 4 & 0 & 0 & 0 & 0 & 34 \\
\hline & 5 & 3 & 4 & 2 & 0 & 0 & 0 & 0 & 14 \\
\hline & 0 & 3 & 1 & 1 & 0 & 0 & 0 & 0 & 5 \\
\hline & 1 & 0 & 2 & 0 & 0 & 0 & 0 & 0 & 3 \\
\hline \multirow[t]{8}{*}{$16-17$} & 0 & 0 & 0 & 0 & 0 & 0 & 0 & 0 & 0 \\
\hline & 0 & 0 & 0 & 0 & 0 & 0 & 0 & 0 & 0 \\
\hline & 0 & 0 & 4 & 0 & 2 & 0 & 0 & 0 & 6 \\
\hline & 0 & 1 & 9 & 2 & 2 & 0 & 0 & 0 & 14 \\
\hline & 1 & 0 & 7 & 2 & 9 & 0 & 0 & 0 & 19 \\
\hline & 0 & 1 & 2 & 1 & 3 & 0 & 0 & 0 & 7 \\
\hline & 0 & 0 & 0 & 0 & 1 & 0 & 0 & 1 & 2 \\
\hline & 0 & 0 & 0 & 0 & 0 & 0 & 0 & 0 & 0 \\
\hline \multirow[t]{8}{*}{$18-19$} & 0 & 0 & 0 & 0 & 0 & 0 & 0 & 0 & 0 \\
\hline & 0 & 0 & 0 & 0 & 0 & 0 & 0 & 0 & 0 \\
\hline & 0 & 0 & 0 & 0 & 1 & 0 & 0 & 0 & 1 \\
\hline & 0 & 0 & 0 & 0 & 0 & 0 & 2 & 0 & 2 \\
\hline & 0 & 0 & 0 & 0 & 5 & 0 & 1 & 0 & 6 \\
\hline & 0 & 0 & 0 & 0 & 1 & 0 & 0 & 0 & 1 \\
\hline & 0 & 0 & 0 & 0 & 0 & 1 & 0 & 0 & 1 \\
\hline & 0 & 0 & 0 & 0 & 0 & 0 & 0 & 0 & 0 \\
\hline Total & 93 & $60^{*}$ & 77 & 22 & 25 & 1 & 3 & 1 & 282 \\
\hline
\end{tabular}

${ }^{*} \mathrm{DP}=$ Dysmenorrhoea Present

${ }^{*} \mathrm{DA}=$ Dysmenorrhoea Absent

Table 3: *Age, Gynaecological Age and Presence or Absence of Dysmenorrhoea among Medical and Nursing Students.

\begin{tabular}{|c|c|c|c|c|c|c|c|c|c|}
\hline \multirow{3}{*}{ Age(Yrs) } & \multicolumn{8}{|c|}{ Gynaecological Age } & \multirow{3}{*}{ Total } \\
\hline & \multicolumn{2}{|c|}{$0-3$} & \multicolumn{2}{|c|}{ 04-Jul } & \multicolumn{2}{|c|}{ 08-Nov } & \multicolumn{2}{|c|}{ Dec-15 } & \\
\hline & DP* & DA* $^{*}$ & DP & DA & DP & DA & DP & DA & \\
\hline \multirow[t]{8}{*}{$<18-18$} & 0 & 0 & 0 & 0 & 0 & 0 & 0 & 0 & 0 \\
\hline & 0 & 2 & 1 & 6 & 0 & 0 & 0 & 0 & 9 \\
\hline & 0 & 1 & 2 & 1 & 0 & 0 & 0 & 0 & 4 \\
\hline & 0 & 0 & 1 & 1 & 0 & 0 & 0 & 0 & 2 \\
\hline & 0 & 0 & 0 & 0 & 0 & 0 & 0 & 0 & 0 \\
\hline & 0 & 0 & 0 & 0 & 0 & 0 & 0 & 0 & 0 \\
\hline & 0 & 0 & 0 & 0 & 0 & 0 & 0 & 0 & 0 \\
\hline & 0 & 0 & 0 & 0 & 0 & 0 & 0 & 0 & 0 \\
\hline \multirow[t]{7}{*}{$19-20$} & 0 & 0 & 0 & 2 & 1 & 0 & 0 & 0 & 3 \\
\hline & 0 & 0 & 6 & 5 & 1 & 1 & 0 & 0 & 13 \\
\hline & 0 & 0 & 8 & 7 & 1 & 2 & 0 & 0 & 18 \\
\hline & 0 & 0 & 2 & 2 & 0 & 0 & 0 & 0 & 4 \\
\hline & 0 & 0 & 1 & 0 & 0 & 0 & 0 & 0 & 1 \\
\hline & 0 & 0 & 0 & 0 & 0 & 0 & 0 & 0 & 0 \\
\hline & 0 & 0 & 0 & 0 & 0 & 0 & 0 & 0 & 0 \\
\hline
\end{tabular}




\begin{tabular}{|c|c|c|c|c|c|c|c|c|c|}
\hline & 0 & 0 & 0 & 0 & 0 & 0 & 0 & 0 & 0 \\
\hline \multirow[t]{8}{*}{$21-22$} & 0 & 0 & 0 & 0 & 1 & 0 & 0 & 0 & 1 \\
\hline & 0 & 0 & 1 & 0 & 8 & 2 & 0 & 0 & 11 \\
\hline & 0 & 0 & 2 & 1 & 10 & 3 & 0 & 0 & 16 \\
\hline & 0 & 0 & 0 & 0 & 3 & 0 & 0 & 0 & 3 \\
\hline & 0 & 0 & 1 & 0 & 1 & 0 & 0 & 0 & 2 \\
\hline & 0 & 0 & 0 & 0 & 0 & 0 & 0 & 0 & 0 \\
\hline & 0 & 0 & 0 & 0 & 1 & 0 & 0 & 0 & 1 \\
\hline & 0 & 0 & 0 & 0 & 1 & 0 & 0 & 0 & 1 \\
\hline \multirow[t]{8}{*}{$23-24$} & 0 & 0 & 0 & 0 & 0 & 0 & 0 & 0 & 0 \\
\hline & 0 & 0 & 0 & 0 & 1 & 0 & 6 & 0 & 7 \\
\hline & 0 & 0 & 0 & 0 & 1 & 0 & 1 & 0 & 2 \\
\hline & 0 & 0 & 0 & 0 & 0 & 0 & 2 & 0 & 2 \\
\hline & 0 & 0 & 0 & 0 & 0 & 0 & 0 & 0 & 0 \\
\hline & 0 & 0 & 0 & 0 & 0 & 0 & 0 & 0 & 0 \\
\hline & 0 & 0 & 0 & 0 & 0 & 0 & 0 & 0 & 0 \\
\hline & 0 & 0 & 0 & 0 & 0 & 0 & 0 & 0 & 0 \\
\hline Total & 0 & 3 & 25 & 25 & 30 & 8 & 9 & 0 & 100 \\
\hline
\end{tabular}

${ }^{*} \mathrm{DP}=$ Dysmenorrhoea Present

${ }^{*} \mathrm{DA}=$ Dysmenorrhoea Absent

Table 4: *Age, Socio-Economic Status, Rural, Urban Setting and School Absentism.

\begin{tabular}{|c|c|c|c|c|c|c|}
\hline \multirow{3}{*}{ Ses } & \multirow{3}{*}{ Age (Yrs) } & \multicolumn{4}{|c|}{ School Absentism } & \multirow{3}{*}{ Total } \\
\hline & & \multicolumn{2}{|c|}{ Yes } & \multicolumn{2}{|c|}{ No } & \\
\hline & & Rural & Urban & Rural & Urban & \\
\hline \multirow[t]{5}{*}{ Upper } & $10-\mathrm{Nov}$ & 0 & 0 & 0 & 0 & 0 \\
\hline & Dec-13 & 0 & 0 & 0 & 1 & 1 \\
\hline & $14-15$ & 0 & 0 & 0 & 0 & 0 \\
\hline & $16-17$ & 1 & 0 & 1 & 0 & 2 \\
\hline & $18-19$ & 0 & 0 & 0 & 0 & 0 \\
\hline \multirow[t]{5}{*}{ Upp-Mid } & $10-\mathrm{Nov}$ & 0 & 0 & 0 & 1 & 1 \\
\hline & Dec-13 & 0 & 0 & 5 & 4 & 9 \\
\hline & $14-15$ & 1 & 3 & 0 & 1 & 5 \\
\hline & $16-17$ & 1 & 0 & 0 & 1 & 2 \\
\hline & $18-19$ & 0 & 0 & 0 & 0 & 0 \\
\hline \multirow[t]{5}{*}{ Middle } & $10-\mathrm{Nov}$ & 0 & 0 & 1 & 0 & 1 \\
\hline & Dec-13 & 1 & 1 & 6 & 16 & 24 \\
\hline & $14-15$ & 4 & 5 & 9 & 31 & 49 \\
\hline & $16-17$ & 2 & 2 & 1 & 5 & 10 \\
\hline & $18-19$ & 0 & 1 & 0 & 0 & 1 \\
\hline \multirow[t]{5}{*}{ Mid-Low } & $10-\mathrm{Nov}$ & 0 & 0 & 0 & 0 & 0 \\
\hline & Dec-13 & 0 & 1 & 0 & 8 & 9 \\
\hline & $14-15$ & 4 & 7 & 13 & 28 & 52 \\
\hline & $16-17$ & 1 & 3 & 4 & 8 & 16 \\
\hline & $18-19$ & 0 & 1 & 0 & 2 & 3 \\
\hline \multirow[t]{2}{*}{ Lower } & $10-\mathrm{Nov}$ & 0 & 0 & 0 & 0 & 0 \\
\hline & Dec-13 & 0 & 1 & 0 & 11 & 12 \\
\hline
\end{tabular}




\section{Journal of Gynecology and Women's Health}

\begin{tabular}{|c|c|c|c|c|c|c|}
\hline & $14-15$ & 5 & 7 & 25 & 24 & 61 \\
\hline & $16-17$ & 3 & 5 & 9 & 1 & 18 \\
\hline & $18-19$ & 0 & 1 & 0 & 5 & 6 \\
\hline Total & & 23 & 38 & 74 & 147 & 282 \\
\hline \multirow[t]{3}{*}{ Age } & Dysmenorrhoea & \multicolumn{2}{|c|}{ DP* } & \multicolumn{2}{|c|}{$\mathbf{D A}^{*}$} & \\
\hline & & $\begin{array}{c}\text { School } \\
\text { Absentism }\end{array}$ & & & & \\
\hline & & Yes & No & & & \\
\hline \multirow[t]{3}{*}{ 10-Nov } & Mild & 0 & 0 & 1 & & 1 \\
\hline & Moderate & 0 & 0 & & & \\
\hline & Severe & 0 & 0 & & & \\
\hline \multirow[t]{3}{*}{ Dec-13 } & Mild & 0 & 6 & 22 & & 51 \\
\hline & Moderate & 3 & 18 & & & \\
\hline & Severe & 1 & 1 & & & \\
\hline \multirow[t]{3}{*}{$14-15$} & Mild & 7 & 18 & 53 & & 171 \\
\hline & Moderate & 15 & 50 & & & \\
\hline & Severe & 14 & 14 & & & \\
\hline \multirow[t]{3}{*}{$16-17$} & Mild & 1 & 2 & 8 & & 48 \\
\hline & Moderate & 9 & 20 & & & \\
\hline & Severe & 8 & 0 & & & \\
\hline \multirow[t]{3}{*}{$18-19$} & Mild & 1 & 0 & 1 & & 11 \\
\hline & Moderate & 0 & 5 & & & \\
\hline & Severe & 2 & 2 & & & \\
\hline Total & & 61 & 136 & 85 & & 282 \\
\hline
\end{tabular}

*DP- Dysmenorrhoea Present

*DA- Dysmenorrhoea Absent

Table 5: *Age, Socio-Economic Status, Rural, Urban Setting and School Absentism among Medical and Nursing Students.

\begin{tabular}{|c|c|c|c|c|c|c|}
\hline \multirow{3}{*}{ Ses } & \multirow{3}{*}{ Age (yrs) } & \multicolumn{4}{|c|}{ School absentism } & \multirow{3}{*}{ Total } \\
\hline & & \multicolumn{2}{|c|}{ Yes } & \multicolumn{2}{|c|}{ No } & \\
\hline & & Rural & Urban & Rural & Urban & \\
\hline \multirow[t]{4}{*}{ Upper } & $<18-18$ & 0 & 0 & 0 & 1 & 1 \\
\hline & $19-20$ & 0 & 1 & 0 & 1 & 2 \\
\hline & $21-22$ & 0 & 4 & 0 & 2 & 6 \\
\hline & $23-24$ & 0 & 0 & 0 & 0 & 0 \\
\hline \multirow[t]{4}{*}{ Upp-mid } & $<18-18$ & 0 & 3 & 0 & 5 & 8 \\
\hline & $19-20$ & 1 & 1 & 1 & 8 & 11 \\
\hline & $21-22$ & 0 & 8 & 0 & 5 & 13 \\
\hline & $23-24$ & 0 & 0 & 0 & 1 & 1 \\
\hline \multirow[t]{4}{*}{ Middle } & $<18-18$ & 0 & 1 & 3 & 2 & 6 \\
\hline & $19-20$ & 1 & 7 & 5 & 6 & 19 \\
\hline & $21-22$ & 1 & 4 & 4 & 3 & 12 \\
\hline & $23-24$ & 0 & 5 & 0 & 3 & 8 \\
\hline \multirow[t]{4}{*}{ Mid-low } & $<18-18$ & 0 & 0 & 0 & 0 & 0 \\
\hline & $19-20$ & 1 & 1 & 4 & 1 & 7 \\
\hline & $21-22$ & 1 & 0 & 3 & 0 & 4 \\
\hline & $23-24$ & 2 & 0 & 0 & 0 & 2 \\
\hline
\end{tabular}




\begin{tabular}{|c|c|c|c|c|c|c|}
\hline Lower & $\begin{array}{l}\text { *There was no girl } \\
\text { in the lower socio- } \\
\text { economic status } \\
\text { group }\end{array}$ & & & & & \\
\hline \multirow[t]{2}{*}{ Total } & & 7 & 35 & 20 & 38 & 100 \\
\hline & & \multicolumn{2}{|c|}{ DP* } & \multicolumn{2}{|c|}{ DA* } & \\
\hline \multirow[t]{2}{*}{ Age } & Dysmenorrhoea & \multicolumn{2}{|c|}{ School Absentism } & & & \\
\hline & & Yes & No & & & \\
\hline \multirow[t]{3}{*}{$<18-18$} & Mild & 0 & 0 & 11 & & 15 \\
\hline & Moderate & 4 & 9 & & & \\
\hline & Severe & 0 & 0 & & & \\
\hline \multirow[t]{3}{*}{$19-20$} & Mild & 1 & 5 & 19 & & 39 \\
\hline & Moderate & 4 & 2 & & & \\
\hline & Severe & 8 & 0 & & & \\
\hline \multirow[t]{3}{*}{$21-22$} & Mild & 1 & 7 & 6 & & 35 \\
\hline & Moderate & 4 & 2 & & & \\
\hline & Severe & 13 & 2 & & & \\
\hline \multirow[t]{4}{*}{$23-24$} & Mild & 0 & 1 & 2 & & 11 \\
\hline & Moderate & 3 & 1 & & & \\
\hline & Severe & 4 & 0 & & & \\
\hline & & 42 & 20 & 38 & & 100 \\
\hline
\end{tabular}

\section{Discussion}

Dysmenorrhoea is a highly prevalent disorder and continues to periodically plague girls / young women. The reported prevalence was $55 \%$ in school and college girls in the study by Hedge [7]. Patel et al. [8] did a study and reported that the burden of dysmenorrhoea was greater than any other gynaecological complaint, and was associated with significant impact. Social disadvantage, co-morbidity with other somatic syndromes and reproductive factors were determinants of this complaint. The frequency of dysmenorrhoea reported by different researchers is difficult to compare because of the wide variations in the diagnostic criteria, age distribution of the girls, the ethnic, cultural backgrounds, different geographic locations and girls frankness in providing correct information. In the present analysis gynaecological age had a positive correlation with dysmenorrhoea, $60.78 \%$ school girls at gyn age 4 to 5 years had dysmenorrhoea. Similar trend was also found in the medical and nursing students with $50 \%$ of girls who had pain at gyn age of 4 to 7 years and $78 \%$ later. There is increased endometrial prostaglandin production in ovulatory cycles and hence more often pain compared to anovulatory cycles. The fact that dysmenorrhea occurred only in ovulatory cycles has withstood the test of time. Age of menarche at 11-12 years in girls from higher economic class and greater severity of dysmenorrhoea with an earlier menarche has been reported earlier also [9]. Zannoni et al. [10] reported that $68 \%$ of the participants complained of dysmenorrhoea, $12 \%$ lost days of school/work monthly because of dysmenorrhoea in a study of 250 cases. Absence from school/work during menses showed an adjusted odds ratio for severe dysmenorrhoea about 28 times greater than those who did not declare absenteism. Banikarim et al. [11] reported 38\% missing school due to dysmenorrhea and 33\% reported missing individual classes. The prevalence of school and work absenteeism provided evidence for the continuing importance of dysmenorrhea as a public health problem of this age group. In the present analysis too many girls reported dysmenorrhea and many remained absent from schools. The pain is difficult to measure in dysmenorrhoea partly because it is usually accompanied by other unpleasant symptoms and partly because the reaction to pain is an individual experience and is affected by the personality of person experiencing pain. In the study by George et al. [5], 28(12\%) had mild pain, $77(33 \%)$ had moderate pain and $41(17.6 \%)$ had severe pain during menstruation. Agrawal et al. [12] studied the prevalence of dysmenorrhea in adolescent girls and reported $79.67 \%$ girls having dysmenorrhea. Most of them, 37.96\%, suffered regularly from severe dysmenorrhea. Bavil et al. [13] after a study about nutrition and physical activity reported a healthier and more favorable nutrition style and more regular physical activity reduced the severity of dysmenorrhea in girls. Therefore, educational measures are required to raise awareness among young women about the effects of proper nutrition and physical activity on the prevention and reduction of dysmenorrhea complications. The sexual maturity of each subject was graded by using the reference photographic plates developed by Tanner. Frequency of dysmenorrhoea increased from $49.6 \%$ at Tanner stage III to $90.83 \%$ at Tanner stage IV ( $\mathrm{P}=0.0001$, significant) and though there were 17 girls of Tanner stage $V$ in the school survey, all of them had dysmenorrhoea putting the frequency at $100 \%$ in the present analysis. Present findings were similar to the study by Klein [14] who had reported that dysmenorrhoea 
increased from $38 \%$ at Tanner stage III to $66 \%$ at Tanner stage $\mathrm{V}$, in girls between 14-15 years, 64\% had dysmenorrhoea which increased to $83.33 \%$ in $16-17$ years old. However at $14-15$ years $50 \%$ of girls in Tanner stage III and $90.12 \%$ of girls in Tanner stage IV had dysmenorrhoea. Similarly, $41.6 \%$ of girls between 16-17 years at Tanner stage III had dysmenorrhoea compared to $96.55 \%$ at Tanner stage IV. Tanner staging influenced occurrence of dysmenorrhoea more at a given age than when age was considered alone. Decades back in the study of dysmenorrhoea by Klein [14] in United States, of the 2699 postmenarcheal girls prevalence of dysmenorrhoea was $59.7 \%$. Of those reporting pain, $14 \%$ described it as severe, $37 \%$ as moderate and $49 \%$ as mild. The prevalence of dysmenorrhoea increased with age, from $39 \%$ in 12 years old to $72 \%$ in 17 years olds. Dysmenorrhoea also increased with sexual maturity from $38 \%$ at age 10 years with Tanner stage III to $66 \%$ at age 10 years with Tanner stage $\mathrm{V}$ and from $31 \%$ one year post menarche to $78 \%$, 5 years post menarche. In the present study, when medical/nursing students were asked in the beginning very few reported dysmenorrhoea, but when asked again they said by denying, they had put an effective end to further questions inspite of the fact they were informed that it was just research. Actual numbers were 3 times more. So the issue of dysmenorrhea needs to be tackled sensitively. More research is needed so that steps could be taken for prevention.

\section{Conclusion}

Dysmenorrhoea was found to be very common. Tanners stage affected dysmenorrhoea more than age. Girls with severe dysmenorrhoea remained absent from school always, though some with mild and moderate too. Decreasing absentism from school, work and help the girls to cope better with this physiological event is the need of hour.

\section{References}

1. Schroeder B, Sanfilippo J (1999) Dysmenorrhoea and pelvic pain in adolescents. Pediatric clinics of North America 46: 555-571.
2. Andrew S, Coco MD (1999) Lancaster General Hospital, Lancaster, Pennsylvania. Primary Dysmenorrhea. Am Fam Physician 60(2): 489496.

3. Johnson J (1988) Level of knowledge among adolescent girls regarding effective treatment for dysmenorrhea. J Adolesc Health Care 93989402.

4. Polat A, Celik H, Gurates B, Kaya D, Nalbant M, et al. (2009) Prevalence of primary dysmenorrhea in young adult female university students. Arch Gynecol Obstet 279(4): 527-532.

5. George NS, Priyadarchini S, Shetty S (2014) Dysmenorrhoea among adolescent girls - characteristics and symptoms experienced during menstruation. Nitte University Journal of Health Science 4(3): 45-52.

6. Tiwari SC, Aditya Kumar, Ambrish Kumar (2005) Development\& standardization of a scale to measure socio-economic status in urban \& rural communities in India. Indian J Med Res 122: 309-314.

7. Hedge K, Desai P, Hazra M (1990) Adolescents Menstrual Patterns. J of obstet Gynaecol 40: 264-269.

8. Patel V, Tanksale V, Sahasrabhojanee M, Gupte S, Nevrekar P (2006) The burden and determinants of dysmenorrhea: a population-based survey of 2262 women in Goa, India. BJOG 113(4): 453-463.

9. Sundell G, Milsom I, Andersch B (1990) Factors influencing the prevalence and severity of dysmenorrhoea in young women. Br J Obstet Gynaecol 97(7): 588-594.

10. Zannoni L, Giorgi M, Spagnolo E, Montanari G, Villa G, et al. (2014) Dysmenorrhea, absenteeism from school, and symptoms suspicious for endometriosis in adolescents. J Pediatr Adolesc Gynecol 27(5): 258-265.

11. Banikarim C, Chacko MR, Kelder SH (2000) Prevalence and impact of dysmenorrhea on hispanic female adolescents. Arch Pediatr Adolesc Med 154(12): 1226-1229.

12. Agrawal AK, Agrawal A (2010) A study of dysmenorrhea during menstruation in adolescent girls. Indian J Community Med 35(1): 59164.

13. Bavil DA, Dolatian M, Mahmoodi Z, Baghban A (2018) A comparison of physical activity and nutrition in young women with and without primary dysmenorrhea. F1000Research.

14. Klein J, Litt I (1981) Epidemiology of Adolescent Dysmenorrhoea. Pediatrics 68(5): 661-664.

\section{Your next submission with Juniper Publishers will reach you the below assets}

- Quality Editorial service

- Swift Peer Review

- Reprints availability

- E-prints Service

- Manuscript Podcast for convenient understanding

- Global attainment for your research

- Manuscript accessibility in different formats

( Pdf, E-pub, Full Text, Audio)

- Unceasing customer service

Track the below URL for one-step submission https://juniperpublishers.com/online-submission.php 